\title{
Incidência e caracterização molecular de badnavírus em bancos de germoplasma de inhame no Brasil
}

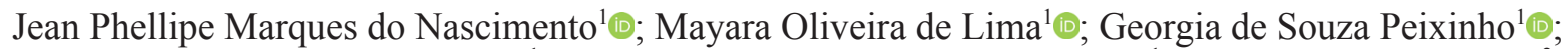 \\ Mayra Machado de Medeiros Ferro ${ }^{1}{ }^{\circledR}$; Sarah Jacqueline Cavalcanti da Silva ${ }^{1} \mathbb{0}$; Elizabeth Ann Veasey ${ }^{2} \mathbb{0}$; \\ Gaus Silvestre de Andrade Lima ${ }^{1} \mathbb{0}$; Iraildes Pereira Assunção ${ }^{1}{ }^{\mathbb{C}}$
}

\begin{abstract}
${ }^{1}$ Setor de Fitossanidade/Campus de Engenharias e Ciências Agrárias, Universidade Federal de Alagoas, CEP 57100-000, Rio Largo, AL-Brasil. ${ }^{2}$ Departamento de Genética, Escola Superior de Agricultura "Luiz de Queiroz”, Universidade de São Paulo (ESALQ-USP), CEP 13418-900, Piracicaba, SP - Brasil

Autor para correspondência: Mayara Oliveira de Lima (mayaralima1811@gmail.com)

Data de chegada: 04/07/2018. Aceito para publicação em: 19/12/2019.
\end{abstract}

$10.1590 / 0100-5405 / 206682$

\section{RESUMO}

Nascimento' J.P.M.; Lima' M.O.; Peixinho' G.S.; Ferro; M.M.M.; Silva' S.J.C.; Veasey’ E.A.; Lima' G.S.A.; Assunção, I.P.. Incidência e caracterização molecular de badnavírus em bancos de germoplasma de inhame no Brasil. Summa Phytopathologica, v.46, n.3, p.242-249, 2020.

Os badnavírus (família Caulimoviridae) possuem genoma de dsDNA semicircular encapsidado em partículas baciliformes. Dioscorea bacilliform virus (DBV) é um importante Badnavirus infectando várias espécies de Dioscorea (inhame) no hemisfério sul. No presente estudo, 235 amostras foliares de inhame foram coletadas em diferentes bancos de germoplasma mantidos pela Escola Superior de Agricultura Luiz (ESALQ/USP), Universidade Federal de Viçosa (UFV) e Universidade Federal do Recôncavo Baiano (UFRB). A incidência média de badnavírus nas amostras avaliadas foi de $75,3 \%$. As análises moleculares e filogenéticas, realizadas a partir de 42 sequências nucleotídicas, da região da RT/RNaseH de badnavírus, revelaram a ocorrência do Dioscorea bacilliform AL virus (DBALV) e Dioscorea bacilliform SN virus (DBSNV) em diferentes espécies de inhame. Até o momento, somente o DBALV havia sido relatado em inhame no Brasil, estando restrito à região Nordeste. Portanto, este é o primeiro relato do DBSNV infectando a cultura do inhame, no país. Além das espécies espissomais, também foram detectadas sequências endógenas, com porcentagem de identidade de nucleotídeos variando entre $89 \%$ e $100 \%$ com endogenous Dioscorea bacilliform virus (eDBV), pertencentes aos grupos 9 e 12. Os resultados obtidos corroboram com a hipótese de que o DBALV e o DBSNV estão presentes em materiais propagativos de inhame e amplamente disseminados no Brasil.

Palavras-chave: Dioscorea spp., Caulimoviridae, sequências endógenas.

\section{ABSTRACT}

Nascimento' J.P.M.; Lima' M.O.; Peixinho' G.S.; Ferro; M.M.M.; Silva' S.J.C.; Veasey' E.A.; Lima' G.S.A.; Assunção, I.P. Incidence and molecular characterization of badnavírus in germplasm banks of yam in Brazil. Summa Phytopathologica, v.46, n.3, p.242-249, 2020.

Badnaviruses (family Caulimoviridae) have semicircular dsDNA genomes encapsidated into bacilliform particles. Dioscorea bacilliform virus (DBV) is an important Badnavirus infecting several species of Dioscorea (yam) in the southern hemisphere. In this study, 235 yam leaf samples were collected from different germplasm banks maintained by "Luiz de Queiroz" College of Agriculture (ESALQ/USP), Federal University of Viçosa (UFV) and Federal University of Recôncavo da Bahia (UFRB). The average incidence of badnavirus in the evaluated samples was $75.3 \%$. Molecular and phylogenetic analyses, carried out from 42 nucleotide sequences, of the badnavirus RT/RNaseH region, revealed the occurrence of Dioscorea bacilliform AL virus (DBALV) and Dioscorea bacilliform SN virus (DBSNV) in different yam species. So far, only DBALV has been reported in yams in Brazil, being restricted to the Northeast region. Therefore, this is the first report of DBSNV infecting yam crop in the country. In addition to the episomal species, endogenous sequences were detected, and the percentage of nucleotide identity varied between $89 \%$ and $100 \%$ with endogenous Dioscorea bacilliform virus (eDBV), belonging to groups 9 and 12. The obtained results corroborate the hypothesis that DBALV and DBSNV are present in yam propagating materials and are widely disseminated in Brazil.

Keywords: Dioscorea spp., Caulimoviridae; endogenous sequences

O inhame (Dioscorea spp.) é suscetível a diversas doenças nas fases de pré e pós-colheita que comprometem a sua produção, armazenamento e exportação (1).

As viroses são de particular importância, uma vez que a produção de mudas é realizada por propagação vegetativa utilizando de pequenas túberas ou pedaços de túberas, que promovem a perpetuação dos vírus e, consequentemente, o aumento da pressão de inóculo (2). Como consequência do acúmulo de vírus no material propagativo, as plantas também perdem o vigor e produzem túberas de baixa qualidade (3).

Doenças virais acometendo o inhame foram inicialmente relatadas na década de 1930, em Serra Leoa e Porto Rico (4). Sintomas brandos e severos de mosaico foram posteriormente relatados em $D$. rotundata na Nigéria (5). Membros dos gêneros Potyvirus, Cucumovirus, Potexvirus e, em destaque pela importância e distribuição geográfica, do gênero Badnavirus (família Caulimoviridae), têm sido descritos em diferentes espécies de inhame $(2,6,7)$.

A família Caulimoviridae engloba vírus de plantas que possuem o genoma formado por DNA de fita dupla (dsDNA), com tamanho de 7,2 a 9,2 Kb (8) e são classificados como pararetrovírus que não se integram ao genoma do hospedeiro para se replicar, não sendo necessário 
então o genoma destes vírus codificar a proteína integrase (9). As sequências virais podem estar integradas aleatoriamente no genoma de plantas hospedeiras e são conhecidas como sequências endógenas de pararetrovirus (Endogenous Pararetroviral Sequences - EPRVs) (10).

As EPRVs de Caulimoviridae cada vez mais têm sido identificadas em muitas espécies de plantas hospedeiras (11). Estas EPRVs apresentam um padrão de arranjo similar com repetições em tandem, duplicações internas, fragmentações e inversão do genoma viral. Estas sequências de pararetrovírus podem resultar em genomas virais parciais e não funcionais, mas também podem promover a ativação de um genoma viral funcional que causará infecção no hospedeiro (10).

De todos os gêneros da família Caulimoviridae, Badnavirus possui o maior número de espécies descritas e caracteriza-se por apresentar partículas baciliformes com 95-130 nm de comprimento e 24-35 nm de diâmetro (12), seu genoma contém uma única molécula dsDNA circular com tamanho aproximado de 7200-7600 pb, que contem descontinuidades sítio-específicas e que podem conter uma região intergênica poli A. Badnavirus é o segundo maior gênero em número de espécies descritas dentre os que possuem genoma composto por DNA, superado apenas pelos Begomovirus.

A primeira espécie de badnavírus caracterizada em inhame foi um isolado obtido de $D$. alata, proveniente da Nigéria, e nomeado Dioscorea alata bacilliform virus (DaBV) (13). Posteriormente, Seal \& Muller (2) em estudos sobre a diversidade molecular de isolados de Badnavirus, infectando inhame, nas ilhas sul do Pacífico identificaram uma nova espécie: Dioscorea sansibarensis bacilliform virus $(2,14,15)$.

Atualmente, sete espécies de badnavírus que infectam Dioscorea spp. são reconhecidas pelo ICTV: Dioscorea bacilliform AL virus (DBALV), Dioscorea bacilliform AL virus 2 (DBALV 2), Dioscorea bacilliform ES virus (DBESV) Dioscorea bacilliform RT virus 1 (DBRTV1), Dioscorea bacilliform RT virus 2 (DBRTV2), Dioscorea bacilliform SN virus (DBSNV) e Dioscorea bacilliform TR virus (DBTRV) (16). No entanto, estudos realizados na África e sul do Pacífico sugeriram a ocorrência de uma alta diversidade de Badnavirus em inhame com a possível presença de até doze espécies (14). O DBALV causa distorção foliar severa e está amplamente disseminado, sendo encontrado em infecções simples e/ou mistas com Yam mosaic virus e Yam mild mosaic virus, ambas espécies de potyvírus (17).

Nesse contexto, o presente estudo teve como objetivo interceptar e identificar molecularmente espécies de badnavírus em cinco espécies de inhame mantidas em três Institutos de ensino dos estados da Bahia, Minas Gerais e São Paulo.

\section{MATERIAL E MÉTODOS}

\section{Obtenção das Amostras}

As amostras das cinco espécies de inhame analisadas foram obtidas nos bancos de germoplasma da Escola Superior de Agricultura Luiz de Queiroz (ESALQ/USP), Universidade Federal de Viçosa (UFV) e Universidade Federal do Recôncavo Baiano (UFRB).

\section{Amplificação da região RT/RNase/H e sequenciamento}

O DNA total das amostras foi extraído a partir da utilização de 100 a $200 \mathrm{mg}$ de tecido foliar, conforme protocolo descrito por Doyle \& Doyle (18). Alíquotas de DNA foram utilizadas para as reações de amplificação por PCR (Polymerase Chain Reaction). Os oligonucleotídeos utilizados foram BadnaFP (5'ATGCCITTYGGIITIAARAAYGCICC-3') e BadnaRP (5'CCAYTTRCAIACISCICCCCAICC-3') (17), os quais amplificam os domínios RT/RNase/H da ORF 3 do genoma
Tabela 1. Espécies, acessos e locais de procedência das amostras de inhame utilizadas neste estudo.

\begin{tabular}{ccc}
\hline $\begin{array}{c}\text { Banco de } \\
\text { Germoplasma }\end{array}$ & Espécie & $\begin{array}{c}\mathbf{N}^{\circ} \mathbf{d e} \\
\text { Acessos }\end{array}$ \\
\hline ESALQ/USP & Dioscorea bulbifera & 44 \\
ESALQ/USP & Dioscorea cayenensis & 72 \\
ESALQ/USP & Dioscorea trifida & 53 \\
UFV & Dioscorea alata & 10 \\
UFRB & Dioscorea rotundata & 4 \\
UFRB & Dioscorea alata & 12 \\
UFRB & Dioscorea trifida & 2 \\
\hline
\end{tabular}

de espécies de badnavírus já descritas. Os produtos de PCR foram purificados utilizando o kit GFX TM PCR DNA and Gel Band Purification Kit (GE Healthcare) e enviados para sequenciamento na Macrogen Inc. em Seul, Coréia do Sul.

Comparação de sequências, análise filogenética e de recombinação

As sequências foram editadas usando o programa CodonCode Aligner (CodonCode Corporation ${ }^{\circledR}$ ) gerando uma sequência consenso de cada um dos isolados analisados, posteriormente, as sequências foram submetidas ao algoritmo BLASTn (Nucleotide Basic Local Alignment Search Tool).

Foram realizadas comparações pareadas entre as sequências obtidas e sequências de badnavírus depositadas no GenBank, com auxílio da ferramenta Sequence Demarcation Tool v. 1.2 (SDT) (19). Em seguida, foi estimada a percentagem de identidade de sequências de nucleotídeos entre os isolados. De acordo com os critérios do ICTV, para determinação de espécies do gênero Badnavirus, foram considerados valores de identidade da RT/ RNase/H superiores a $20 \%(8)$.

As sequências foram alinhadas utilizando o algoritmo MUSCLE, do software MEGA 6 (Molecular Evolutionary Genetics Analysis) (20). As análises filogenéticas de Máxima Verossimilhança (MV) foram obtidas aplicando-se o modelo de substituição de nucleotídeos General Time Reversible com distribuição gama $(\mathrm{GTR}+\mathrm{G})$. A confiabilidade da árvore obtida respeitou a análise boostrap com 1000 repetições.

Análise para detectar locais (breakpoints) de recombinação e possíveis sequências parentais foi realizada utilizando o software RDP v.4.0 (Recombination Detection Program) (21).

\section{RESULTADOS E DISCUSSÃO}

Amplificação da região RT/RNase/H e sequenciamento

Um total de 235 amostras, das diferentes espécies de inhame pertencentes aos três bancos de germoplasma, foram analisadas, das quais 177 testaram positivas para badnavírus, com a amplificação de um fragmento de aproximadamente $580 \mathrm{pb}$. Constatou-se uma incidência de $75,3 \%$, sendo que a amostragem realizada a partir do banco de germoplasma da UFRB apresentou maior incidência $(87,5 \%)$.

Das 177 amostras positivas na PCR, 113 foram enviadas para sequenciamento. Deste total, 42 amostras foram viáveis para a 
obtenção da sequência específica referente aos domínios RT/ RNase/H da ORF 3 de badnavírus.

Constatou-se alta incidência de badnavírus nos três bancos de germoplasma avaliados. Estes resultados corroboram com os encontrado por Lima et al (22), que observaram 93,7\% de incidência de badnavírus ocorrendo em plantios comerciais de inhame na região Nordeste do Brasil. Em ambos estudos, a detecção e incidência foram obtidas por PCR, técnica, que apesar de não ser capaz de discriminar sequências integradas ao genoma da planta das sequências epissomais, ainda é uma ferramenta de uso rotineiro para detecção das espécies pertencentes ao gênero Badnavirus. Portanto, deve-se considerar que a incidência pode ser superestimada e não sendo condizente com a realidade. Indexações realizadas por PCR, em genótipos de inhame, pertencentes ao Centre de Coopération Internationale en Recherche
Agronomique Pour le Développement (CIRAD,França), evidenciaram que $81 \%$ das amostras analisadas estavam infectadas por badnavírus. Entretanto, quando as mesmas amostras foram indexadas, via PASELISA, foi detectada apenas $60 \%$ de incidência de badnavírus, demonstrando que a PCR amplificou sequências endógenas além das sequências epissomais (23).

Para evitar a detecção de sequências endógenas, Silveira et al. (24) realizaram a indexação biológica do Banana streak virus (BSV), via transmissão por cochonilha, em acessos de bananeira do banco de germoplasma da Embrapa Mandioca e Fruticultura. Os resultados demonstraram uma incidência de apenas $20 \%$, valor inferior ao obtido, por PCR, que foi de $87,5 \%$.

Comparação de sequências, e análise filogenética e de recombinação

Tabela 2. Lista de espécies de Badnavirus utilizadas para as comparações de sequências e análise filogenética, com seus respectivos acrônimos e números de acesso no GenBank.

\begin{tabular}{|c|c|c|}
\hline Espécies & Acrônimo & $\mathrm{N}^{\circ}$ de acesso no GenBank \\
\hline Dioscorea bacilliform sansibarensis virus & DBSNV & DQ22073 \\
\hline Dioscorea bacilliform alata virus & DBALV & AM072673 \\
\hline Dioscorea bacilliform alata virus & DBALV & AM072707 \\
\hline Dioscorea bacilliform alata virus & DBALV & AM503392 \\
\hline Dioscorea bacilliform virus & DBV & AM944586 \\
\hline endogenous Dioscorea bacilliform virus & eDBV & KF829956 \\
\hline endogenous Dioscorea bacilliform virus & eDBV & KF829978 \\
\hline endogenous Dioscorea bacilliform virus & eDBV & KF829987 \\
\hline endogenous Dioscorea bacilliform virus & eDBV & KF829975 \\
\hline Commelina yellow mottle virus & CYMV & NC001343 \\
\hline Cacao swollen shoot virus & CSSV & NC001574 \\
\hline Sugarcane bacilliform IM virus & SBIMV & NC003031 \\
\hline Banana streak $O L$ virus & BSOLV & NC003381 \\
\hline Citrus yellow mosaic virus & CYMV & NC003382 \\
\hline Taro bacilliform virus & TBV & NC004450 \\
\hline Kalanchoe top-spotting virus & KTSV & NC004540 \\
\hline Banana streak Mysore virus & BSMV & NC006955 \\
\hline Banana streak $G F$ virus & BSGFV & NC007002 \\
\hline Banana streak virus & BSV & NC007003 \\
\hline Sugarcane bacilliform Mor virus & SBMORV & NC008017 \\
\hline Dracaena mottle virus & DMV & NC008034 \\
\hline Bougainvillea spectabilis chlorotic vein-banding virus & BSCVBV & NC011592 \\
\hline Pelargonium vein banding virus & PVBV & NC013262 \\
\hline Sugarcane bacilliform virus & SBV & NC013455 \\
\hline Rice tungro bacilliform virus & RBTV & X57924 \\
\hline
\end{tabular}

Tabela 3. Ocorrência de Badnavirus em amostras de inhame pertencentes aos bancos de germoplasma analisados.

\begin{tabular}{cccc}
\hline Banco de germoplasma & $\mathbf{N}^{\mathbf{0}}$ amostras testadas & Amostras PCR positivas & Incidência de badnavírus \\
\hline ESALQ/USP & 169 & 129 & $76,3 \%$ \\
UFV & 50 & 34 & $68 \%$ \\
UFRB & 16 & 14 & $87,5 \%$ \\
\hline
\end{tabular}


Tabela 4. Acessos e espécies de inhame mantidos nos bancos de germoplasma utilizados para a detecção de badnavírus e análises filogenéticas.

\begin{tabular}{|c|c|c|}
\hline Acessos & Espécie & Origem \\
\hline CA41 & Dioscorea alata & UFRB* \\
\hline RX4 & Dioscorea alata & $\mathrm{UFV}^{*}$ \\
\hline $\mathrm{RX} 2$ & Dioscorea alata & UFV \\
\hline DC262D & Dioscorea cayenensis & ESALQ/USP* \\
\hline DB351 & Disocorea bulbifera & ESALQ/USP \\
\hline DB65 & Disocorea bulbifera & ESALQ/USP \\
\hline RX1 & Dioscorea alata & UFV \\
\hline STI5 & Dioscorea alata & UFV \\
\hline DC310 & Dioscorea cayenensis & ESALQ/USP \\
\hline CARA5 & Dioscorea alata & UFV \\
\hline DC21C & Dioscorea cayenensis & ESALQ/USP \\
\hline DC2940 & Dioscorea cayenensis & ESALQ/USP \\
\hline PEZ1 & Dioscorea alata & UFV \\
\hline PEZ2 & Dioscorea alata & UFV \\
\hline MOE5 & Dioscorea alata & UFV \\
\hline MIMO5 & Dioscorea alata & UFV \\
\hline PEZ3 & Dioscorea alata & UFV \\
\hline JAPE4 & Dioscorea alata & UFV \\
\hline FLO4 & Dioscorea alata & UFV \\
\hline MOE2 & Dioscorea alata & UFV \\
\hline DC572 & Dioscorea cayenensis & ESALQ/USP \\
\hline DCT3 & Dioscorea alata & UFV \\
\hline JAPE2 & Dioscorea alata & UFV \\
\hline JAPE3 & Dioscorea alata & UFV \\
\hline PEZ4 & Dioscorea alata & UFV \\
\hline DC13D & Dioscorea cayenensis & ESALQ/USP \\
\hline DC268 & Dioscorea cayenensis & ESALQ/USP \\
\hline DC252 & Dioscorea cayenensis & ESALQ/USP \\
\hline FLO3 & Dioscorea alata & UFV \\
\hline DC85 & Dioscorea cayenensis & ESALQ/USP \\
\hline DC201 & Dioscorea cayenensis & ESALQ/USP \\
\hline FLO1 & Dioscorea alata & UFV \\
\hline DC69 & Dioscorea cayenensis & ESALQ/USP \\
\hline DC86 & Dioscorea cayenensis & ESALQ/USP \\
\hline DC96 & Dioscorea cayenensis & ESALQ/USP \\
\hline DC56C & Dioscorea cayenensis & ESALQ/USP \\
\hline DC56 & Dioscorea cayenensis & ESALQ/USP \\
\hline DCT1 & Dioscorea alata & UFV \\
\hline CARA3 & Dioscorea alata & UFV \\
\hline DCT2 & Dioscorea alata & UFV \\
\hline DB379B & Disocorea bulbifera & ESALQ/USP \\
\hline
\end{tabular}

*ESALQ/USP - Escola Superior de Agricultura Luiz de Queiroz/Universidade de São Paulo; UFV - Universidade Federal de Viçosa; UFRB - Universidade Federal do Recôncavo Baiano.
Análise de comparações de sequências pareadas revelaram que cinco sequências descritas neste trabalho apresentaram porcentagem de identidade de nucleotídeos variando entre $83-98 \%$ com isolados de Dioscorea bacilliform AL virus (AM503392, AM072707 e AM072673), enquanto que 36 sequências apresentaram identidade nucleotídica entre 89-100\% com badnavírus endógenos (EPRVs) ou também chamados de endogenous Dioscorea bacilliform virus (eDBV), conforme nomenclatura proposta por Staginnus et al. (26). Destas sequências, 34 apresentaram maior porcentagem de identidade nucleotídica com eDBVs do grupo 9 (KF829987 e KF829975), conforme classificação proposta por Kenyon et al. (15), e com um isolado de Dioscorea bacilliform virus (DBV - AM944586). No entanto, duas sequências, obtidas no presente estudo, apresentaram identidade de nucleotídeos com eDBVs pertencente ao grupo 12, proposto por Umber (26), cujo os números de acesso são KF829956 e KF829978. Foi observado ainda que a sequência DB379B, obtida a partir de amostras de Dioscorea bulbifera, apresentou identidade de $85 \%$ com isolado de Dioscorea bacilliform sansibarensis virus (DBSNV - DQ822073), descrito em inhame na África (2). Portanto, este é o primeiro relato de DBSNV no Brasil sendo que, até o momento, somente o DBALV havia sido descrito (22).

As análises filogenéticas revelaram que os 42 isolados de DBSNV, provenientes dos bancos de germoplasma monitorados, pertenciam a quatro grupos distintos. No grupo I, 34 isolados obtidos de $D$. cayenensis e $D$. alata, procedentes dos bancos de germoplasma da ESALQ/USP e UFV, agruparam com badnavírus endógenos eDBV9 (15) e com um isolado de DBV. No grupo II, apenas dois isolados oriundos da espécie $D$. bulbifera, obtidos do banco de germoplasma da ESALQ/USP, agruparam com isolados endógenos eDBV12 (26). No grupo III, cinco isolados provenientes de D. alata e D. cayenensis, mantidos nos três bancos de germoplasma, agruparam com três isolados do DBALV, espécie relatada em inhame no Brasil (27), enquanto que no grupo IV um isolado obtido de D. bulbifera, procedente do banco de germoplasma da ESALQ, agrupou com o DBSNV, espécie, até então, não relatada no Brasil.

Diante dos resultados obtidos, foi possível constatar a presença do DBALV e DBSNV nos acessos de inhame mantidos nos distintos bancos de germoplasma avaliados.

O primeiro relato de DBALV, em inhame, no Brasil, ocorreu nos estados da Bahia e Pernambuco (27). Posteriormente, um estudo sobre a variabilidade genética de isolados de badnavírus em Dioscorea spp., provenientes de áreas produtoras dos estados de Alagoas, Paraíba e Pernambuco, sugeriram que DBALV ocorria, exclusivamente, em inhame na região Nordeste do $\operatorname{Brasil}(22,28)$. Nessa região, o DBALV foi detectado em $D$. alata e $D$. cayenensis, encontrando-se amplamente disseminado devido à constante substituição de material propagativo (túberas) e a proximidade entre as áreas de cultivo (16). Pesquisas sobre incidência e distribuição de vírus que infectam inhame em países da África e Sul do Pacífico revelaram que DBALV também é prevalente nas áreas de plantio comercial de inhame $(14,15,29,30)$.

O isolado DB359, obtido de D. bulbifera, proveniente do banco de germoplasma da ESALQ/USP, foi identificado como sendo pertencente à espécie DBSNV. Este vírus foi originalmente descrito no Benin, na África, causando sintomas de deformação e mosaico foliar (2). Posteriormente, o DBSNV também foi relatado em amostras de $D$. alata e D. rotundata, provenientes da Nigéria, Gana, Togo e Benin (14). Diante da amostragem e análises das espécies de inhame mantidas nos bancos de germoplasma, constatou-se a primeira ocorrência do DBSNV no Brasil. Até então, haviam somente relatos da ocorrência do DBALV, 


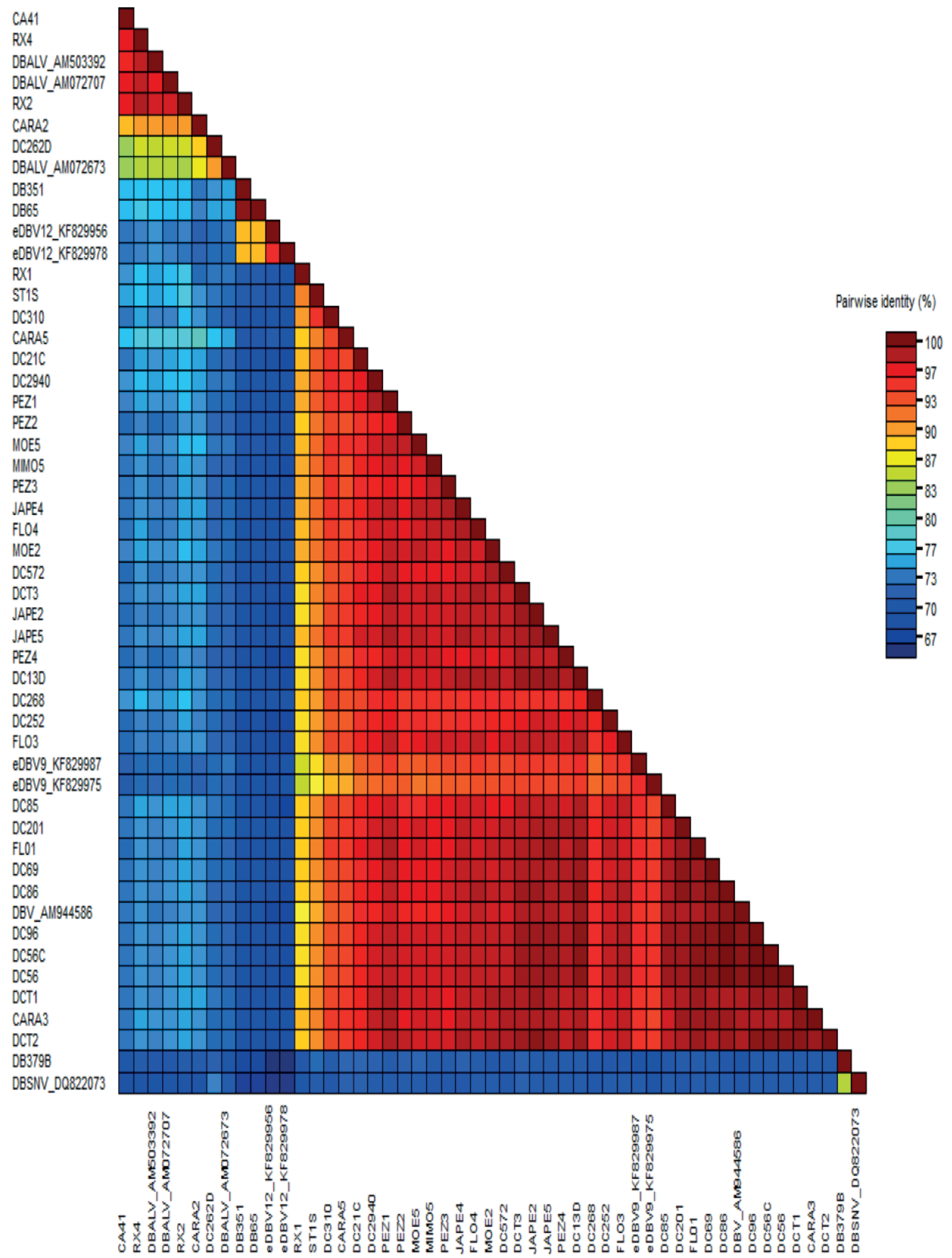

Figura 1. Porcentagem de identidade e comparações pareadas de sequências nucleotídicas da região RT/RNase dos isolados de Dioscorea bacilliform alata virus (DBALV) e Dioscorea bacilliform sansibarensis virus (DBSNV) com outras sequências de espécies de badnavírus disponíveis no GenBank (Matriz bidimensional). 


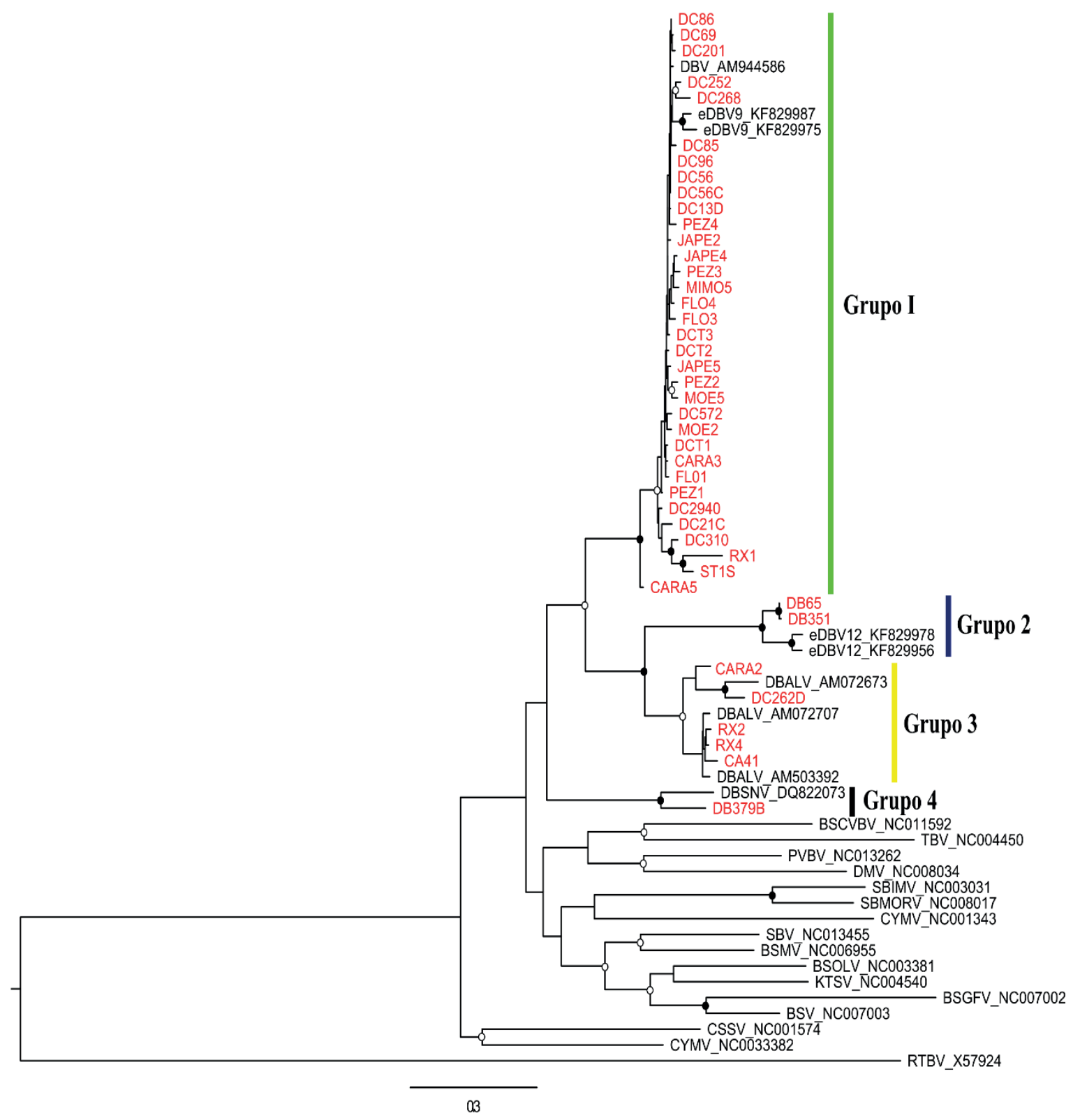

Figura 2. Árvore filogenética de Máxima Verossimilhança baseada em sequências da região RT/RNase de isolados de Badnavirus provenientes de amostras de inhame obtidas durante levantamentos realizados nos bancos de germoplasmas e outras espécies de Badnavirus disponíveis no GenBank. O Rice tungro bacilliform virus (RTBV), gênero Tungrovirus, foi utilizado como grupo externo.

em inhame, na Região Nordeste do Brasil $(22,27,28)$. Este, também, constitui o primeiro relato de DBSNV em D. bulbifera, sugerindo que, assim como DBALV, a espécie viral não possui hospedeiras específicas dentro do gênero Dioscorea.

Apesar do ICTV reconhecer sete espécies de badnavírus capazes de infectar inhame, estudos baseados em PCR e RCA indicaram elevada diversidade destes vírus na costa sul do Oceano Pacífico, África, sugerindo a ocorrência de pelo menos 4 outras espécies de possíveis badnavírus infectando Dioscorea spp. $(16,29)$. Esta alta diversidade deve-se, em parte, devido a existência de um grande número de espécies de inhame como D. alata, $D$. cayenensis, D. rotundata, $D$. sansibarensis em áreas de cultivo no continente africano, e $D$. bulbifera, $D$. dumedorum, $D$. numularia e $D$. penthaphylla nas ilhas do sul do Pacífico $(13,14,15,29)$. Além disso, esta grande diversidade também pode refletir a alta variabilidade das espécies de badnavírus infectando inhame. Por exemplo, a frequência de mutação estimada para populações de DBALV, provenientes do Nordeste do Brasil, é em torno de $10^{-4}$, semelhante àquelas encontradas para outros vírus de DNA e RNA (28).

Os demais isolados analisados durante o levantamento demonstraram alta identidade com sequências de badnavírus endógenos (eDBV), dos quais 34 isolados agruparam com eDBVs do grupo 9 (15) e com um isolado de Dioscorea bacilliform virus - DBV, proveniente do Benin (AM944586), enquanto que dois isolados agruparam com eDBVs do grupo 12 (26). O isolado de DBV (BN4dr/AM944586), utilizado durante a realização do levantamento, foi descrito como sendo uma possível nova espécie de badnavírus que infecta inhame em regiões da África ocidental (14), que, posteriormente, foi descrito como eDBVs do 
grupo 9, conforme classificação definida por Kenyon (15). Portanto, de acordo com Seal et al. (23), para diferenciar se sequências como eDBVs estão integradas ao genoma do inhame ou presentes como sequências epissomais, testes adicionais como PAS-ELISA, ISEM e Southern Blotting são recomendados para confirmar a sua presença nos acessos dos bancos de germoplasma avaliados, e verificar a probabilidade dessas sequências serem ativadas, culminando em possíveis infecções.

A presença de sequências virais endógenas (EPRVs) integradas em genomas de plantas tem sido relatada para uma ampla gama de famílias botânicas, das quais podem ser citadas: Musaceae, Solanaceae e Poaceae $(11,31)$. Porém, para espécies da família Dioscoreaceae, relatos destas sequências integradas em seu genoma ainda são escassos. As análises de sequências de amostras de inhame, provenientes da região do sul do Pacífico, indicaram uma possível presença de sequências de badnavírus integradas em genomas de inhame (15). Bousalem et al (29) analisaram 121 sequências provenientes de inhame, obtidos de regiões do Caribe, América do Sul e África e detectaram a presença de 12 espécies pertencentes ao gênero Badnavirus e aventaram a possibilidade da presença de EPRVs no genoma da planta. Estudos realizaram a confirmação e caracterização de sequências endógenas (eDBV) integradas ao genoma de espécies de inhame, pertencentes ao complexo D. cayenensis-rotundata $(2,26)$. No entanto, a natureza infecciosa dos eDBV, relatados para inhame, ainda não está totalmente estabelecida.

Há poucos relatos de EPRVs capazes de gerar partículas infecciosas, pois a maioria destas não é capaz de infectar a hospedeira (11). Há ainda relatos de que EPRVs podem conferir vantagens ao seu hospedeiro, fornecendo resistência aos seus vírus cognatos (2). A detecção confiável de espécies de badnavírus de inhame representa um desafio, uma vez que é necessário utilizar ferramentas que possam detectar e diferenciar as sequências epissomais das sequências integradas. A técnica de PCR, bem como a sorológica têm sido amplamente utilizadas para detecção de badnavírus em amostras de inhame $(4,32)$. Contudo, não podem ser aplicadas para detecção de sequências endógenas pelo fato de não fornecer uma diferenciação das sequências epissomais e integradas. Técnicas como PCR-Imunocaptura já foram relatadas como sendo capaz de distinguir sequências epissomais das EPRVs de BSV, porém para inhame a utilização desta técnica não forneceu resultados confiáveis (2). Uma abordagem alternativa utilizando RCA (Rolling circle amplification) como método de diferenciação de sequências epissomais e integradas de BSV, em cultivares de banana (Musa spp.), sendo possível inclusive detectar de maneira diferencial sequências integradas de Sugarcane bacilliform virus (SCBV), em cana de açúcar, e Cauliflower mosaic virus (CaMV), em nabo, mostrou-se bastante eficiente (32). Como observado para BSV, esta técnica pode ser utilizada para detecção de formas epissomais de badnavírus no inhame.

Os resultados obtidos no presente estudo demonstram a presença de DBALV e DBSNV nos bancos de germoplasma avaliados. A detecção de DBALV pode ser explicada pelo fato de que os acessos de D. alata e D.caynensis, disponíveis nos Bancos de Germoplasma, foram, em grande parte, oriundos da região Nordeste, onde altos níveis de incidência de DBALV são registrados. No entanto, não se pode descartar a hipótese de que DBALV tenha sido incorporado aos Bancos de Germoplasma por meio da introdução de material propagativo, visto que os acessos são mantidos em cultivo protegido.

Embora este seja o primeiro relato de DBSNV infectando inhame no Brasil, não se pode afirmar que sua existência no país seja recente, uma vez que, até então, os estudos de incidência de badnavírus que infectam inhame estavam restritos apenas à região Nordeste, onde é relatada prevalência do DBALV. Diante dessa constatação, torna-se de extrema importância à continuidade de estudos que possam fornecer informações mais precisas sobre a ocorrência de DBSNV em áreas produtoras do país, afim de possibilitar o uso de medidas de controle efetivas visando evitar a dispersão para áreas livres da ocorrência destas duas espécies de badnavírus.

Apesar de Bousalem et al. (29) relatarem a detecção de um evento de recombinação entre dois isolados de badnavírus, DeBV-B e DeBV-A, obtidos de $D$. alata, as análises realizadas não detectaram a ocorrência de recombinação, estando esse fato possivelmente relacionado com a pequena região genômica analisada.

\section{AGRADECIMENTOS}

Os autores agradecem ao Conselho Nacional de Desenvolvimento Tecnológico e Científico (CNPq), a Coordenação de Aperfeiçoamento de Pessoal de Nível Superior (Capes) e a Fundação de Amparo à Pesquisa do Estado de Alagoas (FAPEAL) pelo apoio nas pesquisas.

\section{REFERÊNCIAS}

1. Mantell, S.H. Integrated use of micropropagation and conventional propagation Techniques for the production of certified seed tubers of tropical yams (Dioscorea spp.). In: Proceedings of the Southern Asian Regional Workshop on Propagation techniques for Commercial Crops of the Tropics. Ho Chi Minh City, 1993.

2. Seal, S.; Muller, E. Molecular analysis of a full-length sequence of a new yam badnavirus from Dioscorea sansibarensis. Archives of Virology, Chatham Maritime. v. 152, p. 819-825, 2007.

3. Amusa, N.A.; Adegbita, A.A.; Muhammed, S.; Daiyewu, R. Yam diseases and its management in Nigeria. African. Journal of Biotechnology, Ibadan v. 2, p. 497-502, 2003.

4. Cook, A.A. Diseases of tropical and sub tropical vegetables and other plants. New York: Hafner Press, 381p. 1978.

5. Terry, E.R. Incidence, symptomatology, and transmission of a yam virus in Nigeria. In: Proceedings of the 4th symposium of the international society for tropical root crops, 1976. Cali, Ed. J. Cock, R. Mcintyre E M. Graham, 1976. p. 170-173.

6. Odu, B.O.; Hughes, J.D’a.; Asiedu, R.; Ng, N.Q.; Shoyinka, S.A.; Oladiran, O.A. Responses of white yam (Dioscorea rotundata) cultivars to inoculation with three viruses. Plant Pathology, Croydon v. 53, p. 141-147, 2004.

7. Odu, B.O.; Asiedu, R.; Shoyinka, S.A.; Hughes, J.d'A. Reaction of White Guinea yam (Dioscorea rotundata Poir.) genotypes to virus diseases in four agroecological zones in Nigeria. Journal of Phytopatology, Ibadan v. 154, p. 688-693, 2006.

8. Geering, A.D. W.; Hull, R. Family Caulimoviridae. In: King A.M.Q.; Adams M.J.; Carstens E.B.; Lefkowitz, E.J. Virus Taxonomy. 9th Report of the International Committee on Taxonomy of Viruses. London UK. Elsevier Academic Press. p. 429-443, 2012.

9. Bhat, A.I.; Hohn. T.; Selvarajan, R. Badnaviruses: The Current Global Scenario. Viruses, Kerala. 2016

10. Gayral, P.; Iskra-Caruana, M. Phylogeny of Banana streak virus Reveals Recent and Repetitive Endogenization in the Genome of Its Banana Host (Musa sp.). Journal of Molecular Evolution, Montpellier. v. 69, p. 65-80, 2009.

11. Geering, A.D.; Scharaschkin, T.; Teycheney, P.Y. The classification and nomenclature of endogenous viruses of the family Caulimoviridae. Archives of Virology, Bruce. v. 155, n. 1, p. 123-31, 2010.

12. Fauquet, C.M.; Mayo, M.A.; Maniloff, J.; Desselberger, U.; Ball, L.A. Virus taxonomy. Eighth Report of the International Committee on Taxonomy of Viruses. Amsterdam. Elsevier. 2005.

13. Phillips, S.; Hull, R.; Briddon, R.W.; Brunt, A.A. The Partial Characterization of a Badnavirus Infecting the Greater Asiatic or Water Yam (Dioscorea alata). Journal of Phytopatholology, Babardos. v. 147, p. 265-269, 1999.

14. Eni, A.O.; Hughes, J'd.; Asiedu, R.; Rey, M.E. Sequence diversity among Badnavirus isolates infecting yam (Dioscorea spp.) in Ghana, Togo, Benin and Nigeria. Archives of Virology, Ibadan v.153, p. 2263-2272, 2008.

15. Kenyon, L.; Lebras, B.S.; Seal, S.E. Yams (Dioscorea spp.) from the South Pacific Islands contain many novel badnaviruses: implications for international movement of yam germplasm, Archives of Virology, Chatham Maritime . v. 3, p.877-889, 2008 
16. Bömer, M.; Rathnayake, A.I.; Visendi, P.; Silva, G.; Seal, S.E. Complete genome sequence of a new member of the genus Badnavirus, Dioscorea bacilliform RT virus 3, reveals the first evidence of recombination in yam badnaviruses. Arch Virol 163, 533-538. 2018.

17. Yang, I.C.; Hafner, G.J.; Dale, J.L.; Harding, R.M. Genomic characterisation of taro bacilliform virus. Archives of Virology, Brisbane. v. 148, p. 937-949, 2003

18. Doyle, J.J.; Doyle, J.L. Isolation of plant DNA from fresh tissue. Focus, Ithaca. v.1, p.13-15, 1991

19. Muhire, B.; Martin, D. P.; Brown, J.K.; Navas-Castillo, J.; Moriones, E.; Zerbini, F.M.; Rivera-Bustamante, R.; Malathi, V.G.; Briddon, R.W.; Varsani, A. A genome-wide pairwise-identity-based proposal for the classification of viruses in the genus Mastrevirus (family Geminiviridae). Archives of virology, v. 158, p. 1411-1424. 2013.

20. Tamura, K.; Stecher, G.; Peterson D.; Filipski, A.; Kumar, S. MEGA6: Molecular Evolutionary Genetics Analysis Version 6.0. Molecular Biology and Evolution, v. 30, p. 2725-2729, 2013.

21. Martin, D.P.; Murrell, B.; Golden, M.; Khoosal, A.; Muhire, B. RDP4: Detection and analysis of recombination patterns in virus genomes. Virus Evolution, p. 1-5, 2015.

22. Lima, J.S.; Lima, A.T.M.; Castilho-Urquiza, G.P.; Silva, S.J.C.; Assunção, I.P.; Michereff, S.J.; Zerbibi, F.M.; Lima, G.S.A. Variabilidade genética de isolados de badnavírus infectando inhame (Dioscorea spp.) no Nordeste do Brasil. Tropical Plant Pathology, Recife. v.38, p.349-353, 2013.

23. Seal, S.; Turaki, A.; Muller, E.; Kumar, P.L.; Kenyon, L.; Filloux, D.; Galzi, S.; Lopez-Montes, A.; Iskra-Caruana, M.L. The prevalence of badnaviruses in West Africa yams (Dioscorea cayenensis-rotundata) and evidence of endogenous pararetrovirus sequences in their genomes. Virus Research. Chatham Maritime, 2014.

24. Silveira, D.G.; Meissner-Filho, P.E.; Soares, T.M.; Sanches, N.F.; Figueiredo, D.V.; Brioso, P.S.T. Indexação biológica de genótipos de bananeira para o Banana streak virus. Summa Phytopathol. Botucatu, v. 34, n. 2, p. 172-174, 2008.
25. Staginnus, C.; Iskra-Caruana, M.L.; Lockhart, B.; Hohn, T.; Richert-Poggeler, K.R. Suggestions for a nomenclature of endogenous pararetroviral sequences inplants. Archives of Virology, Frankfurt. n.154, p.1189-1193, 2011 .

26. Umber, M.; Filloux, D.; Muller, E.; Laboureau, N.; Galzi, S.; Roumagnac, P.; Iskra-Caruana, M.L. Pavis, C.; Teycheney, P.Y,.; Seal, S.E. et al. The genome of African yam (Dioscorea cayenensis-rotundata complex) hosts endogenous sequences from four distinct badnavirus species. Molecular Plant Pathology, Petit-Bourg, (Guadeloupe) pp.12137, 2014.

27. Andrade, G.P. Diagnóstico fitossanitário da cultura do inhame (Dioscorea spp.) em áreas produtoras do nordeste do Brasil. Tese (Doutorado em Fitopatologia) - Universidade Federal Rural de Pernambuco (UFRPE). Recife, PE, 2007.

28. Guimarães, K.M., Silva, S.J.C., Melo, A.M., Ramos-Sobrinho R, Lima. J.S., Zerbini, F.M., Assunção, I.P., Lima, G.S.A. Genetic variability of badnaviruses infecting yam (Dioscorea spp.) in northeastern Brazil. Tropical Plant Pathology, v. 40, p.111-118, 2015

29. Bousalem, M.; Durand, O.; Scarcelli, N.; Lebas, B.S.; Kenyon, L.; Marchand, J.L.; Lefort, F.; Seal, S.E. Dilemmas caused by endogenous pararetroviruses regarding the taxonomy and diagnosis of yam (Dioscorea spp.) badnaviruses: analyses to support safe germplasm movement. Archives of Virology Petit-Bourg. v. 154, p.297-314, 2009.

30. Asala, S.; Alegbejo, M.D.; Kashina, B.D.; Banwo, O.O. Distribution and incidence of viruses infecting yam (Dioscorea spp.) in Nigeria. Global Journal of Bio-Science \& Biotechnology, Zaria. vol 1(2), 163-167, 2012

31. Iskra-Caruana, M.L.; Baurens, F.C.; Gayral, P.; Chabannes, M. A four-partnerplant-virus interaction: enemies can also come from within. Molecular Plant Microbe Interactions, v.23, 1394-1402 p., 2010.

32. James, A.P.; Geijskes, R.J.; Dale, J.L.; Harding, R.M. Development of a novel rolling-circle amplification technique to detect Banana streak virus which also discriminates between integrated and episomal virus sequences. Plant Disease, Brisbane. v.95, p.57-62, 2010. 